\title{
Maria Toscano, A madre da casa da avó - os nomes infinitos do ser
}

\section{Graça Capinha}

\section{(2) OpenEdition}

\section{Journals}

Edição electrónica

URL: http://journals.openedition.org/rccs/1243

DOI: $10.4000 /$ rccs. 1243

ISSN: 2182-7435

Editora

Centro de Estudos Sociais da Universidade de Coimbra

\section{Edição impressa}

Data de publição: 1 dezembro 2002

Paginação: 149-152

ISSN: 0254-1106

\section{Refêrencia eletrónica}

Graça Capinha, "Maria Toscano, A madre da casa da avó - os nomes infinitos do ser », Revista Crítica de Ciências Sociais [Online], 64 | 2002, posto online no dia 01 outubro 2012, consultado o 22 setembro 2020. URL : http://journals.openedition.org/rccs/1243; DOI : https://doi.org/10.4000/rccs.1243 


\section{Recensões}

\section{Caroline Moser; Fiona Clark (orgs.), Victims, Perpetrators or Actors? Gender, Armed Conflict and Political Violence. London/New York: Zed Books, 2001, 208 pp.}

A maioria das medidas de construção da paz levadas a cabo pela Organização das Nações Unidas, pelos Estados e por algumas ONGs limita-se aos domínios tradicionais da manutenção da paz, reconstrução de infra-estruturas e ajuda humanitária de emergência. Neste tipo de iniciativas, a participação das mulheres é frequentemente negligenciada. No entanto, coexistem com estas práticas formas alternativas de construção da paz, que incluem a prática da não-violência, o reconhecimento e respeito pelos direitos humanos ou a capacitação das mulheres nas esferas económica, cultural, social e política, contribuindo para uma abordagem integrada que não exclua nenhum grupo (Mazurana e McKay, 1999: 1).

Victims, Perpetrators or Actors? Gender, Armed Conflict and Political Violence é uma obra centrada precisamente numa abordagem da relação entre diferença sexual e conflitos armados. Este livro é o produto de uma conferência global sobre "Diferença Sexual, Conflitos Armados e Violência Política”, realizada em Junho de 1999 no Banco Mundial, em Washington D.C., que contou com a participação de representantes de ONGs e agências internacionais oriundas da América Latina, Médio Oriente, África, Ásia e Europa. Caroline Moser é antropóloga social e especialista em políticas sociais, além de coordenadora de um projecto do Banco Mundial sobre a violência na Colômbia. De entre os trabalhos já publicados podem referir-se as obras Violence in a Post-Conflict Context:
Urban Poor Perceptions from Guatemala (Moser e McIlwaine, 2001) e Gender Planning and Development: Theory, Practice and Training (Moser, 1995). Fiona Clark é investigadora independente, colaborou com C. Moser no Banco Mundial e foi responsável pela conferência que deu origem a esta publicação.

O livro divide-se em sete partes temáticas, contendo um total de treze capítulos. Após a introdução das organizadoras (Moser e Clark), seguem-se dois textos de enquadramento (Cockburn e Moser) e dez estudos de caso agrupados por tipos de abordagens (Turshen, Zarkov - as políticas de vitimização: abuso sexual e violência; Sharoni, Butalia - identidade sexual, poder e actuação; Ibañez - mulheres enquanto actores nos conflitos armados e violência política; Meertens - questões de identidade em situações de deslocamento; Cordero, Mulholland, Moser e McIlwaine - actuação e identidade na construção de uma paz sustentável; e Krog - diferença sexual e violência na Verdade e Reconciliação), cada um apresentando uma narrativa sobre aspectos particulares de uma dimensão de identidade sexual dos conflitos armados ou da violência política.

O objectivo de fundo desta obra é o de reflectir sobre os papéis, interesses e necessidades específicos de mulheres e homens enquanto actores em situações de conflito armado e de violência política. As autoras pretenderam, desta forma, contribuir para uma mudança na abordagem dos conflitos armados e da violência política, que, 
apesar de ser um tópico já clássico na literatura, não tem incluído a reflexão sobre a especificidade da participação efectiva das mulheres. Com efeito, tem sido dominante nas análises da violência política e dos conflitos armados a adopção de estereótipos sexuais. Por um lado, verifica-se a omissão da participação das mulheres nas forças armadas, guerrilhas, forças paramilitares ou nas operações de paz (Enloe, 1993). Por outro, tem-se recorrido à estereotipificação, ao essencialismo, à universalização ou à divisão simplista dos papéis, rotulando os homens como perpetradores da violência e actores activos durante os conflitos (associados à agressividade) e as mulheres como vítimas e defensoras da paz (associadas à passividade) (Boutros-Ghali, 1992; United Nations, 1996; Yuval-Davis, 1997; Lentin, 1997; Kelly, 2000; Jacobs et al., 2000). Esta lacuna, na opinião das autoras, tem importantes consequências para o conflito em si mesmo e para a fase de reconstrução pós-bélica.

Ho-Won Jeong, em Peace and Conflict Studies - An Introduction (2000: 77), considera que as identidades sexuais são um elemento essencial da compreensão da estrutura social e da origem da violência, uma vez que são usadas como justificação de um modelo de relações humanas hierárquicas. A construção de categorias femininas e masculinas, antiteticamente construídas no contexto ocidental, está directamente ligada às relações de poder decorrentes $\mathrm{da}$ atribuição de significados às identidades sexuais. Esta categorização foi usada para criar uma hierarquia de valores e relações de poder desiguais entre os seres humanos, encarada pelas feministas como fruto do sistema patriarcal, que perpetua a cultura da violência a vários níveis da sociedade (Boulding, 1976). Neste livro, e em particular na análise contextual de Cockburn, é analisada a importância das relações de poder decorrentes de construções locais de masculinidades e feminilidades, e do modo como estas estão ligadas às questões de actuação e participação, através da comparação das diferentes leituras que podemos obter quando adoptamos uma de três abordagens possíveis na análise de conflitos armados e violência política - assumir as diferenciações sexuais, ignorar estas diferenciações ou problematizar estas mesmas diferenciações. Optando por uma abordagem feminista, a autora aplica-a a quatro momentos do conflito - antes de irromper a violência armada, durante a guerra, em processos de construção da paz e em períodos de pós-guerra - concluindo que, em cada fase, as actuações feminina e masculina (especificamente contextualizadas nos sistemas existentes), as identidades que geram e as relações de poder entre elas, comprometem os papéis de mulheres e homens enquanto actores sociais. A mesma preocupação pela formulação de um quadro operacional que garanta a inclusão de preocupações específicas das mulheres nas negociações de paz e na reconstrução pós-bélica marca o segundo capítulo de enquadramento de Caroline Moser. A fundamentação lógica para este quadro começa pelo reconhecimento de que tanto o conflito como a violência são moldados por diferentes papéis, relações de poder e identidades sexuais atribuídos segundo estereótipos. Desta forma, mulheres e homens enquanto actores sociais sentem a violência e o conflito de diferentes modos, têm diferentes necessidades e interesses e diferente acesso a recursos como o poder e a tomada de decisão. A autora descreve este quadro em quatro secções: categoriza a violência (política, económica e social), adoptando assim uma visão holística e criticando a tendência de classificar a violência relativa a identidades sexuais como "social”, argumentando que o posicionamento de mulheres e homens em termos destes três tipos de violência é moldado pela 
atribuição de papéis sexuais na sociedade, enquanto vítimas ou perpetradores; identifica factores causais da violência em diferentes níveis (individual, inter-pessoal, institucional e estrutural), com o objectivo de verificar por que motivo a violência afecta de modo diferente mulheres e homens; examina os custos e as consequências do conflito e da violência; e, finalmente, apela ao desenvolvimento de uma abordagem política integral uma vez que, até muito recentemente, a análise da violência e as intervenções de redução da violência não têm incluído uma perspectiva centrada sobre a identidade sexual, tendendo a dar prioridade a um tipo de violência em particular e a um conjunto de factores causais e grupos alvo. Esta necessidade de uma abordagem política integral, mais alargada, é partilhada por outras autoras, como Dyan Mazurana e Susan McKay (1999).

Estas grelhas analíticas são tratadas em vários estudos de caso, que se dividem em duas áreas de discussão: a questão da actuação, identidade e relações de poder nos conflitos armados e na violência política e a questão da identidade e tipos de actuação na reconstrução pós-bélica e construção da paz. Nas duas abordagens o principal objectivo é o de questionar ou tentar inverter estereótipos, circunscrevendo os estudos a um contexto geográfico específico. Na primeira linha de discussão, incluem-se temas como a desconstrução das representações sexuais nos conflitos (caso da ex-Jugoslávia, analisado por Dubravka Zarkov), a aplicação da categorização da violência (desenvolvida anteriormente por Moser) e a análise de factores causais dos conflitos (casos do Ruanda e de Moçambique, analisados por Meredeth Turshen), o conflito enquanto espaço de capacitação das mulheres e de reflexão sobre as prioridades dos movimentos de mulheres (estudos de Simona Sharoni e
Urvashi Butalia), o desafio ou a inversão de estereótipos durante e após os conflitos armados e violência política (estudo de caso de Ana Cristina Ibañez sobre as mulheres ex-combatentes em El Salvador). A segunda linha de discussão prende-se com o período pós-conflito armado e violência política, de reconstrução e construção da paz, analisando os processos através dos quais mulheres e homens reconstroem as suas vidas e renegoceiam os seus papéis sexuais (explícito no estudo de caso de Donny Meertens), através de novos modelos de organização, de formas inovadoras de trabalho, de determinação de níveis de confiança em organizações locais (Isabel Coral Cordero, Marie Mulholland, Caroline Moser e Cathy McIlwaine).

No entanto, um dos principais objectivos deste livro, senão o principal, é o de apelar à necessidade de desenvolver uma perspectiva inclusiva e integrada, que tenha em vista a redução de todos os tipos de violência, que tenha presente que mulheres e homens sofrem de forma diferente estes tipos de violência, e que necessitam de respostas diferentes. Este apelo está bem presente no último capítulo sobre testemunhos de violência na Comissão de Verdade e Reconciliação na África do Sul e sobre formas de reconstrução de uma sociedade saída de um período de conflito armado e violência política, em particular quando Krog argumenta que "(a) simples presença de mulheres e do seu modo de pensar instintivo e inclusivo [no processo de reconstrução] fará com que as pessoas actuem pelo menos num contexto mais amplo" (p. 216).

Esta obra resulta num contributo de grande valor para os estudos sobre conflitos armados e violência política por dois motivos. Em primeiro lugar, porque tenta ultrapassar a imagem simplista e universalista das mulheres enquanto principais vítimas durante os períodos de conflito e 
enquanto "construtoras naturais da paz", recusando a abordagem essencialista que de há uns anos a esta parte tem caracterizado alguma da literatura feminista sobre movimentos pacifistas. A importância da participação concreta das mulheres em iniciativas de redução da violência e de reconstrução pós-bélica tem sido justificada de diversas formas, desde o pacifismo 'natural' inerente ao feminino, que por vezes se torna redutor por reproduzir estereótipos que deveriam ser ultrapassados, passando pelo sentido maternal de responsabilidade, crenças religiosas, militarismo ou luta colectiva contra a violência e opressão. No entanto, a construção da paz tem uma especificidade cultural e local, tal como os conflitos armados que a tornam necessária. E por não se tratar de uma fórmula ou definição global, as iniciativas locais de redução da violência, reconstrução ou reabilitação pós-conflito, que incluem as abordagens tradicionais de construção da paz ou iniciativas alternativas, devem ser tidas em consideração e desenvolvidas. É desta especificidade que nos dá conta Victims, Perpetrators or Actors? Gender, Armed Conflict and Political Violence. Em segundo lugar, a importância do contributo deste livro justifica-se pela tentativa de manter e espelhar a diversidade que caracteriza o movimento de mulheres ou o feminismo em geral. Na opinião de Mazurana e McKay (1999), tal como as abordagens que não consideram as diferenciações sexuais privilegiam as experiências masculinas e negligenciam os impactos específicos dos conflitos e da violência sobre as mulheres, as análises que empregam categorias monolíticas de "mulheres" e "experiências de mulheres" falham por não considerarem a diversidade e estratificação entre as próprias mulheres, que resultam em diferentes respostas, mecanismos e posições individuais num determinado contexto.

\section{Tatiana Moura}

\section{Referências Bibliográficas}

Boulding, Elise (1976), The Underside of History: A View of Women through Time. Boulder, CO: Westview.

Boutros-Ghali, Boutros (1992), An Agenda for Peace. New York: United Nations Publications.

Enloe, Cynthia (1993), The Morning After: Sexual Politics at the End of the Cold War. Berkeley: University of California Press.

Jacobs, Susie et al. (2000), States of Conflict: Gender, Violence and Resistance. London/ New York: Zed Books.

Jeong, Ho-Won (org.) (2000), Peace and Conflict Studies - An Introduction. Burlington: Ashgate.

Kelly, Liz (2000), "Wars against Women: Sexual Violence, Sexual Politics and the Militarised State", in Susie Jacobs et al. (2000), States of Conflict: Gender, Violence and Resistance. London/New York: Zed Books.

Lentin, Ronit (org.) (1997), Gender and Catastrophe. London/New York: Zed Books.

Mazurana, Dyan; McKay, Susan (1999), Women and Peacebuilding. Montreal: International Centre for Human Rights and Democratic Development.

Moser, Caroline (1995), Gender Planning and Development: Theory, Practice and Training. New York/London: Routledge.

Moser, Caroline; McIlwaine, Cathy (2001), Violence in a Post-Conflict Context: Urban Poor Perceptions from Guatemala. Washington, D.C.: World Bank Publications.

United Nations Organization (1996), An Inventory of Post-Conflict Peace-Building Activities. New York: UNO.

Yuval-Davis, Nira (1997), Gender and Nation. London: Sage Publications. 


\section{Maria Toscano, A madre da casa da avó - os nomes infinitos do ser. Coimbra: Pé de Página, 2002, 55 pp. +65 pp.}

A autora deste livro, Maria Toscano, é uma personalidade muito diversificada nos seus interesses. Socióloga de formação e carreira, tem igualmente vindo a explorar várias formas de expressão artística, que vão desde a arte dramática, à música, ao canto. Como ela própria se deixa dizer na recente Colectânea de Poesia, também publicada pela Pé de Página, no final de 2001, estamos perante uma "insatisfeita, buscadora da fala poética”.

Este livro, a madre da casa da avó-os nomes infinitos do ser-e penso que posso usar aqui o humor a que a Maria Toscano nos habituou - é assim uma espécie de "dois em um". Não é, contudo, como manobra publicitária que essa "substância” poética nos surge, mas antes como uma estrutura escolhida pela poeta para construir uma obra feita de vários fios, várias sequências de poemas, que se procuram entrelaçar. De resto, a imagem da trança dos fios de cabelo - dos fios de poema - está visualmente marcada na própria apresentação gráfica da obra. Os dois livros, a madre da casa da avó e os nomes infinitos do ser, obrigam-nos a esse movimento, ao movimento do entrançar: a uma leitura que nos leva pela exploração espacial, a juntar-se, mas a ultrapassar, a mera linearidade sequencial. O fim faz-se princípio e o princípio faz-se fim, porque, tal como se afirma, no último verso do último poema de os nomes infinitos do ser, o importante é "perdurar": continuar a fazer e a desfazer essa trança, que é também o acto de relação entre os infinitos fios da nossa existência.

a madre da casa da avó começa com uma epígrafe de Paulo Nozolino:
Nada

Antes não havia nada. Nada senão

[oliveiras e céu.

Alentejo pobre, terra de alguns. Hoje, [apesar do progresso,

o nada é maior. Continuo a voltar lá

para sonbar e me desiludir.

para endurecer e fortalecer o cinismo

necessário à sobrevivência.

Do nada aproveito tudo

A infância de Maria Toscano andou pelo Alentejo e essa marca é muito visível na sua poesia e penso que sobretudo neste livro, mais do que em qualquer outro da autora. A pobreza e o despojamento, de que nos fala Nozolino a propósito do Alentejo, são sem dúvida as grandes características desta obra, uma obra que é uma espécie de procura do máximo no mínimo. Tal como Nozolino, Maria Toscano parece dizer-nos: "do nada aproveito tudo". Há um poeta inglês de que gosto muito, Basil Bunting, que queria escrever uma poesia apenas com aquilo a que chamava "lean words" - palavras esguias. Penso que, neste livro, o objectivo da Maria Toscano foi exactamente esse: escrever com palavras esguias. O primeiro poema, "asas de palavras”, acaba agradecendo o Desprendimento e a Contemplação. É uma espécie de introdução a todo o livro. Diz a poeta: "desprendo-me pelo ar, em vozes-força; em sílabas de espanto/de Futuro”. Sílabas de uma poesia que procura os cosmos na trivialidade, no quotidiano, nas "miudezas do dia-a-dia". Sílabas "repetidas - sem repetição”, a ecoar Gertrude Stein, que afirmava isso mesmo: se só há repetição, a repetição não existe. E não existe, antes de tudo o mais, porque as sílabas, as palavras que repetimos, são transformadas na 
experiência da nossa própria voz. Todas as palavras são mutantes e essa mutação, em que todos participamos ao adequá-las à infinita diversidade da experiência humana, é, como afirma a poeta, "o risco certo à incerta mão”. A mão desconhece o resultado da transformação em que participa e daí as sílabas de espanto de Futuro. Por exemplo, no poema "vozes insinuantes" (p. 13), a mutação surge ao nível da sintaxe, já que a poeta procura a proliferação numa ambiguidade construída com a sintaxe e a morfologia. Estas vozes são "- umas, por barbas ditas/outras, por infantas sabidas". Ou seja, podemos ler apenas a pausa do fim de verso e teremos: "vozes, por barbas ditas". Mas também, na ausência de pontuação, podemos fazer o encavalgamento para o verso seguinte e leremos: "vozes, por barbas ditas outras" - ou seja, vozes feitas diferentes pelas barbas (metonímia do masculino) que as dizem. Quanto a "sabidas", podemos ler como adjectivo ou como verbo: vozes sabidas por infantas, ou "infantas sabidas". A trança das palavras faz-se e desfaz-se, "conforto de estilhaços/desatou nossos laços/(quase nó)”, lê-se noutro poema (p.16). Algo se afirma aqui como crucial para esta escrita - aliás tal como para toda a escrita de Maria Toscano: falo da necessidade da voz nesta poesia. O tom coloquial, a aguda ironia, o jogo com a ambiguidade (como no exemplo que venho de referir) necessitam absolutamente da encenação. O carácter performativo e dramático desta poesia liga-se sem dúvida a essa busca do poético que a nossa autora também tem explorado na linguagem teatral - e assim se encontra uma forma híbrida.

Outra característica desta escrita prende-se com aquilo a que Wallace Stevens chamaria "uma mente de gelo", uma característica que se manifesta sobretudo quando se trata o grande tema da tradição lírica, o amor. E a poeta atreve-se a tratá-lo, mas usando sempre uma atitude de distanciamento, por vezes quase gélida de tão lúcida - mas nunca menos lírica. $\mathrm{O}$ poema "sem te esperar" é um dos meus favoritos e, além do distanciamento referido, encontramos nele mais um traço que me parece também fundamental na obra: a presença de uma linguagem no feminino, aqui no acto doméstico de velar a luz da janela. A janela, que é também metáfora da linguagem, através da qual vemos o mundo: uma linguagem a que se põem borlas e cortinas (um pano cénico, estou tentada a chamar-lhe), velando o real, de forma subtil, para o poder olhar calma e lucidamente. Diz o poema:

sem te esperar

te espero, presumida

das vantagens da minha janela. desabotoo-lhe borlas e cortinas desvelo-lhe véus de primavera descerro grades. Cercas, medos idos converto-os em florões de espera:

sem te esperar, te espero, amanbecida sem rancores nem odores de quimera.

Brincando com a glosa e a redondilha maior, também a grande tradição da poesia oral e popular - uma tradição tão rica e tão esquecida - nos há-de surgir neste livro, marcando esta escrita pela raiz que é o Alentejo. Veja-se apenas um fragmento do poema "num pergaminho de plumas":

num pergaminho de plumas

encontro o meu coração

couraçado por chuvas, olhos

de água da ingratidão

ou convertido num missal

de fé e santa benção

num pergaminho de linbo

reeencontro meu coração:

é de cristal cristalino é de barro feito à mão de estanbo do tempo antigo

e de muita comoção 
A redondilha, a glosa, o Alentejo reportam-nos à simplicidade que é a maior complexidade do olhar, um olhar que nos termina a primeira parte deste livro com o poema longo que lhe dá título, "a madre da casa da avó" - um poema profundamente marcado pela domesticidade do feminino, mas, sobretudo, um poema marcado pelo olhar límpido da criança e do seu espanto:

havia um rasto de oliveiras

no campo estonteante

campo aberto

jorrado torrado a eito

forro de cortiça e azeitonas

padrão de oiros

campo pão

esbugalhado nos olhos

de bestas, mulas morenas

lentas.

cheiro a chão.

campo maior

do pão.

Campo maior desta escrita, sem dúvida. $\mathrm{Na}$ segunda parte deste livro, encontramos "a praça das palavras", um conjunto de poemas dedicados ao espaço do quotidiano, mas de pendor metapoético, a encher-se de todos os detalhes da praça e da espera. Diz Maria Toscano: "não falo do falar. falo/da Fala, dos nomes da seiva e da oração perfeita” (p. 33) - uma oração que, afinal, ainda falta. No penúltimo poema da sequência, "com as árvores", é precisamente essa falta da oração perfeita que levará a poeta a afirmar: "vou com as árvores/raiz/ bico de viço interior”. E, finalmente, em "a praça das palavras", como que a fechar o círculo, de novo as palavras esguias, esguiamente se desenham quase à margem da página, desenhando-nos a visão da poeta sobre o seu próprio acto poético:

$$
\begin{gathered}
\text { sem remorsos } \\
\text { sem freios } \\
\text { sem ameias }
\end{gathered}
$$

com os sentidos pelos plátanos fundidos revisito a praça, dita, das palavras fantasias de almas perenes serenos lírios-quase-perfeitos

$$
\begin{gathered}
\text { plátanos } \\
\text { outros sentidos ungidos } \\
\text { a preceito. } \\
\text { (p. 55) }
\end{gathered}
$$

Agora, viremos a página e viremos o livro ao contrário. Outro livro que é o mesmo e o contrário, outras palavras, outros poemas a entrançar-se no texto - magicamente, poderíamos dizer, já que o entrançar é acto religioso e mitopoético de toda a representação da criação. Uma forma mágica presente até no próprio ADN (!)... Este entrançar das palavras a surgir como uma espécie de arcaico que marca, ainda e inexoravelmente, a nossa modernidade.

os nomes infinitos do ser apresenta três secções no seu início: "o sonhar”, "o amar", "o arder”. Desde logo, a magia do número 3, mas também, desde logo, religiosamente, o desejo, o acto, e a queda. A esfera semântica da magia encontramo-la logo na escolha lexical do primeiro poema: oráculos, duendes, gnomos. Toda uma plêiade de truques e de artifícios para presentificar o real, para o abrir à revelação e, contudo, termina o poema, "é intensa esta palavra/que não sai”. Como se o poema fosse esse momento permanentemente anterior ao acto: o arco esticado antes de a seta ser lançada.

"o amar" traz-nos já o voo da seta, o acto de relação. Eé uma definição irónica, a que Maria Toscano nos dá:

o desenho de um amor não tem vértices pontos de fuga, de fricção

o esboço da paixão não tem molduras

só tons, colmo, flama, tonturas e bumidade em combustão. 
Finalmente, em "o arder", o pecado: afasta-se o distanciamento, que só se mantém no minimalismo dos versos, mas os poemas tornam-se excessivos, quase "demasiado" íntimos, poderíamos dizer, como neste fragmento:

nos ombros

a marca de abraços

e um rebulhão

braços, coxas, languidão.

de novo

tontura atordoada

me sobe, do ventre,

sem perdão

búmus

de linguas fartas

me escorrem das mãos.

(...)

Outro fio de poemas entra agora na trança, "o arrancar da raiz", a exigir uma desterritorialização, um outro espaço do "eu" e da palavra, um outro espaço para o acto de relação: "emigro/desligo/desligo-me//do dentro de ti", diz a poeta (p. 40). Fica "o lembrar", fica o espaço vazio, "esse o corpo/ outrora vela acesa” - mas um espaço vazio que se enche de possibilidade. Por isso "o perdurar" é a última parte deste livro que, não o esqueçamos, volta ao princípio na volta do livro. A trança feita, que se desfaz, e que será feita de novo. Diz a poeta:

esta é a história com letra pequena e nada que se lhe acrescente

(...)

esta é a bistória com sentido:

porta que se abra

(...)

Entre a Anunciação e a Ressurreição, a voz e o corpo, sempre repetidos, sempre trança feita e desfeita, na vida e no poema: "perdurar", "nada e tudo poder", conclui a autora. E voltamos à epígrafe de Nozolino: “do nada aproveito tudo". Em última instância, e como Maria Toscano parece demonstrar-nos, é essa possibilidade mesma que a arte nos pode oferecer: da fragilidade e da impotência humanas, tudo aproveitar - para celebrar a grandiosidade da existência na terra.

\section{Graça Capinba}

